\title{
Transmission of health information on leprosy from children to their families in an urban centre
}

\author{
M. S. JACOB*, D. AMAR* A. CHRISTOPHER* \& \\ J. S. KEYSTONE† \\ *St John's Medical College Hospital, Bangalore, Karnataka, S. India; \\ and $†$ The Tropical Disease Unit, The Toronto Hospital, 200 Elizabeth \\ Street, Toronto, Ontario, Canada, M5G 2C4
}

Accepted for publication 24 February 1994

\begin{abstract}
Summary A health education study utilizing a homework assignment was carried out in a private secondary school in Bangalore, South India, to determine whether health information about leprosy would be transferred from children to their families. After a pre-test questionnaire on knowledge and attitude about leprosy was administered to 3 Standard VII classes and their family members, a different comprehensive health education session was given to each class: (i) leprosy plus a homework assignment; (ii) leprosy alone; and (iii) tuberculosis alone.'A post-test questionnaire was administered to all participants 1 month later.

Of the 118 children and 229 family members who entered the study, almost $80 \%$ of the participants completed it. The children in the leprosy-educated groups showed significant improvement in knowledge compared with controls, but no change in their attitude towards leprosy. Although post-test responses of household members showed modest improvement in knowledge about leprosy, attitudes remained the same or worsened. The homework assignment did not appear to improve the transmission of health information to household members.

This study showed that the knowledge level of family members in South India could be improved modestly by educating their children about leprosy. However, attitudes towards leprosy were unaffected or worsened.
\end{abstract}

\section{Introduction}

In 1990 Premkumar and his colleagues reported on a controlled study in a rural area of South India which was designed to determine whether health information given to schoolchildren would influence the knowledge and attitudes of their families about leprosy. ${ }^{1}$ Although significant improvement in knowledge about leprosy was detected in

\footnotetext{
Correspondence: The Toronto Hospital, Tropical Disease Unit, 200 Elizabeth Street, ENG-214, Toronto, Ontario, Canada M5G 2C4
} 
the educated children, no transmission of information to their family members was detected. Also, the attitudes of children who had been educated about leprosy appeared to be adversely affected by the health education session.

The present study was an extension of the initial study with several important differences. The study population was larger and came from an urban centre. In addition, a homework assignment was added in order to encourage children to discuss with their families health information acquired in the classroom.

\section{PATIENTS AND METHODS}

In 1990 a health education study was carried out in a private secondary school in Bangalore, Karnataka, S. India. Children attending the school were drawn from middleclass families living in Bangalore (70\% of the male household heads were officers, clerks, professional persons or skilled labourers, more than $80 \%$ of these individuals had matriculated from secondary school, and the majority had post-secondary school education).

There were 700 children in the school which had classes from Standard I to X. A Standard VII class (aged 11-13) was chosen for the investigation. Males made up 50\% of the classes. Approximately $85 \%$ of the children came from Christian families, with the remainder from Hindu and Muslim.

During the first part of the study, the knowledge and attitude of 3 classrooms of children and their family members concerning leprosy was tested by means of a standardized questionnaire which was administered in English by a health care worker. The 32 questions either required a yes/no response or were the open-ended type for which the evaluator filled in the response. This pre-test questionnaire did not focus specifically on leprosy but contained a number of questions about tuberculosis and AIDS. It tested attitudes and several areas of knowledge about leprosy such as the aetiology of leprosy, its curability, contagiousness and recognition. In addition to knowledge acquisition as a means to determine transfer of information from children to their families, we questioned household members about their familiarity with leprosy and where that knowledge was acquired.

The participants were not informed about the purpose of the study or what might be expected of them in the future -1 month after the pre-test questionnaire was administered, the 3 Standard VII classes received a comprehensive educational session. Class (A) learned about leprosy and was given a homework assignment on the subject which they were specifically asked to discuss with their family members. Class (B) received the identical educational session on leprosy but was not given a homework assignment. Class (C) was given a comprehensive educational session on tuberculosis.

The children and their family members were re-tested with the identical questionnaire (post-test) 1 month after the educational sessions, and in the same fashion as at the start of the study.

As noted in Table 1, there were no significant differences between the 3 classes of children and their families with respect to age, gender, education level and occupation: 41 of 45 children in a class were enrolled in group A, 36 of 50 in another class were enrolled in Group B and 27 of 44 children in a 3rd class were enrolled in group C. Students not enrolled in each class were those who were absent on the day that the pretest questionnaire was administered. The mean age of the children in groups A, B and C 
Table 1. Demographic characteristics of the household members of the 3 groups of children who completed this study

\begin{tabular}{|c|c|c|c|}
\hline \multirow[b]{2}{*}{ Characteristics } & \multicolumn{3}{|c|}{ Educational session } \\
\hline & $\begin{array}{l}\text { Leprosy plus } \\
\text { homework }(\mathrm{A}) \\
\quad(n=76)\end{array}$ & $\begin{array}{l}\text { Leprosy } \\
\text { alone }(\mathrm{B}) \\
(n=73)\end{array}$ & $\begin{array}{c}\text { Tuberculosis }(\mathrm{C}) \\
\quad(n=80)\end{array}$ \\
\hline Mean age (years): & $37 \cdot 2 \pm 9 \cdot 53$ & $39 \cdot 1 \pm 10 \cdot 4$ & $37 \cdot 3 \pm 8 \cdot 9$ \\
\hline \multicolumn{4}{|l|}{ Sex: } \\
\hline M & $40(53)$ & $36(50)$ & $37(46)$ \\
\hline $\mathrm{F}$ & $36(47)$ & $37(50)$ & $43(54)$ \\
\hline \multicolumn{4}{|l|}{ Education: } \\
\hline literate & $5(6)$ & $5(6)$ & $3(4)$ \\
\hline primary & $1(1)$ & $3(4)$ & $1(1)$ \\
\hline secondary & $5(6)$ & $10(13)$ & $11(15)$ \\
\hline matriculate & $12(15)$ & $23(29)$ & $19(26)$ \\
\hline P.U.C./technical diploma & $18(24)$ & $17(21)$ & $18(25)$ \\
\hline graduate/prof. degree & $26(36)$ & $18(22)$ & $15(21)$ \\
\hline post-graduate/prof. degree & $9(12)$ & $4(5)$ & $5(8)$ \\
\hline \multicolumn{4}{|l|}{ Occupation: } \\
\hline housewife & $22(30)$ & $30(38)$ & $22(32)$ \\
\hline student & $2(3)$ & $4(5)$ & $3(4)$ \\
\hline manager & $7(10)$ & $1(1)$ & $4(6)$ \\
\hline officer & $7(10)$ & $4(5)$ & $6(9)$ \\
\hline clerk & $7(10)$ & $8(10)$ & $9(13)$ \\
\hline professional & $16(22)$ & $10(12)$ & $13(19)$ \\
\hline skilled labourer & $7(10)$ & $8(10)$ & $8(11)$ \\
\hline unskilled labourer & $1(1)$ & $2(2)$ & $0(0)$ \\
\hline agricultural worker & $0(0)$ & $0(0)$ & $0(0)$ \\
\hline shop/factory owner & $3(4)$ & $7(9)$ & $4(6)$ \\
\hline other & & $6(8)$ & \\
\hline
\end{tabular}

was $12 \cdot 2,12 \cdot 8$ and $12 \cdot 5$ years, respectively. The gender ratio and religious composition were similar for both groups. Statistical analysis was carried out by the Wilxocon signed rank test and $\chi^{2}$ analysis.

\section{Results}

In total, 118 of 139 children (85\%) in the 3 classes and 229 of the 269 family members $(85 \%)$ entered the study. Of those who were entered, 89 of the children and 183 of the adults completed the study with a compliance of $75 \%$ and $80 \%$ for children and adults, respectively. Overall, 93 of $139(67 \%)$ family units completed the study. Family unit compliance was $69 \%$ in group A, $60 \%$ in group B and $72 \%$ in group C. The family members and students who entered, but did not complete the study were unavailable for follow-up or refused to take part in the second half of the study.

In the analysis of the results of the pre-test questionnaire no significant differences were found in knowledge level or attitude concerning leprosy between the study groups of children or their families except that the 2 groups of children who were taught about leprosy feared the disease more than the control children at the start of the study. 
Table 2. Knowledge level of schoolchildren and their families about leprosy

\begin{tabular}{|c|c|c|c|c|c|c|}
\hline \multirow[b]{3}{*}{ Sample questions } & \multicolumn{6}{|c|}{$\%$ Response } \\
\hline & \multicolumn{3}{|c|}{ Children } & \multicolumn{3}{|c|}{ Families } \\
\hline & A & B & $\mathrm{C}$ & A & B & $\mathrm{C}$ \\
\hline \multicolumn{7}{|c|}{1 Cause of leprosy: germs/sneezing } \\
\hline pre: & 15 & 24 & 24 & 14 & 18 & 38 \\
\hline post: & $72 *$ & $58^{*}$ & $57 *$ & $58^{*}$ & $49^{*}$ & 37 \\
\hline heredity & & & & & & \\
\hline pre: & 46 & 63 & 64 & 57 & 60 & 70 \\
\hline post: & $16^{*} \dagger$ & 61 & $38^{*}$ & 61 & $31^{*}$ & $44^{*}$ \\
\hline sexual transmiss & & & & & & \\
\hline pre: & $34 \dagger$ & 56 & 70 & 50 & 68 & 52 \\
\hline post: & $36 \dagger$ & 49 & 64 & $55 \dagger$ & $48^{*} \dagger$ & $76^{*}$ \\
\hline \multicolumn{7}{|c|}{2 Can leprosy be acquired by touching? (no) } \\
\hline pre: & 52 & 66 & 60 & 46 & 40 & 54 \\
\hline post: & 48 & 63 & 66 & 42 & 54 & 69 \\
\hline \multicolumn{7}{|c|}{3 Who spreads leprosy? (infectious persons only) } \\
\hline pre: & 18 & 26 & 36 & 50 & 25 & 27 \\
\hline post: & $73 *+$ & $52 * \dagger$ & 30 & $81^{* \dagger}$ & $53^{*}$ & 39 \\
\hline \multicolumn{7}{|c|}{$\begin{array}{l}4 \text { How to detect leprosy? } \\
\text { (\% of } 14 \text { signs/symptoms identified) }\end{array}$} \\
\hline pre & 31 & 29 & 26 & 27 & 31 & 34 \\
\hline post: & 32 & $44^{*}$ & $45^{*}$ & 37 & 36 & 46 \\
\hline \multicolumn{7}{|c|}{5 Can leprosy be cured? (yes) } \\
\hline pre: & 93 & 89 & 94 & 75 & 82 & 71 \\
\hline post: & 100 & 100 & 92 & 90 & 82 & 89 \\
\hline
\end{tabular}

,$+{ }^{*} p<0.05 \chi^{2}$ analysis: ${ }^{*}$, (pre-test $v s$ post-test within the group); $\dagger$, (result $v s$ control group $\mathrm{C}$ ).

( ), correct response

In the evaluation of the post-test questionnaire responses, children in groups $\mathrm{A}$ and $\mathrm{B}$ (those educated about leprosy) showed significant improvement in knowledge in 2 and 3 of the 5 areas tested, respectively. In group B, knowledge improved in all but 1 area. On the other hand, the control group of children (C) showed significant improvement in 2 areas only and no tendency to improvement in other areas. Compared with group $\mathrm{C}$, the post-test knowledge level of those who had been educated about leprosy was statistically significantly improved in 2 areas (the aetiology and transmission of leprosy). In spite of improvement in their knowledge base, the attitudes of the children were basically unchanged. In fact, in Group A there was a tendency towards a worsening of attitudes since after the health education session, fewer of these children were willing to employ persons who had been successfully treated for leprosy or invite them to eat in their homes. This change in attitude did not reach statistical significance.

An analysis of the post-test responses of household members in all 3 groups showed that there was improvement in knowledge concerning leprosy. Statistically significant improvement in knowledge of the aetiology of leprosy was noted in all 3 groups and about transmission groups $\mathrm{A}$ and B. However, there was a trend to improvement in knowledge in at least 2 other areas in both $\mathrm{A}$ and $\mathrm{C}$ household members. With 2 exceptions, there were no significant differences in the post-test responses between the 
Table 3. Attitudes of school children and their families about leprosy

\begin{tabular}{|c|c|c|c|c|c|c|}
\hline \multirow[b]{3}{*}{ Questions } & \multicolumn{6}{|c|}{$\%$ Response } \\
\hline & \multicolumn{3}{|c|}{ Children } & \multicolumn{3}{|c|}{ Families } \\
\hline & A & B & $\mathrm{C}$ & A & B & $\mathrm{C}$ \\
\hline \multicolumn{7}{|c|}{$\begin{array}{l}1 \text { Leprosy feared most (Yes, compared with TB, } \\
\text { cancer and AIDS) }\end{array}$} \\
\hline pre: & $12 \dagger$ & $7 \dagger$ & 39 & 4 & 4 & 3 \\
\hline post: & $0 \dagger$ & $11 \dagger$ & 27 & 1 & 3 & 3 \\
\hline \multicolumn{7}{|c|}{2 Leprosy like other diseases (yes) } \\
\hline pre: & 30 & 48 & 30 & 33 & 34 & 30 \\
\hline post: & 52 & 55 & 40 & $54^{*}$ & $57^{*}$ & 45 \\
\hline \multicolumn{7}{|c|}{$\begin{array}{l}3 \text { Would you offer food in your home to a person } \\
\text { with leprosy? (yes) }\end{array}$} \\
\hline pre: & 45 & 37 & 36 & 62 & 59 & 51 \\
\hline post: & 27 & 40 & 30 & 35 & 63 & 64 \\
\hline \multicolumn{7}{|c|}{$\begin{array}{l}4 \text { Would you employ a person who had been } \\
\text { successfully treated for leprosy (yes) }\end{array}$} \\
\hline pre: & 48 & 55 & 61 & 47 & 38 & 52 \\
\hline post: & 36 & 52 & 55 & 39 & 47 & 49 \\
\hline
\end{tabular}

${ }^{*}, \dagger p<0.05 \chi^{2}$ analysis: ${ }^{*}$, (pre-test $v s$ post-test within the group); $\dagger$, (result $v s$ control group C).

leprosy-educated groups and controls. Overall, among family members there was no significant change in attitude except in group A families who, like their children, showed a worsening of attitude about employing and sharing food with a person who had been successfully treated for leprosy.

When we enquired from family members whether they had received information about leprosy from their children, $55 \%$ of group A, $63 \%$ of group B and $42 \%$ of group C indicated that their child had brought home information from school approximately 1 month before the follow-up questionnaire was administered. In all, $16 \%$ of the family members of group A, $22 \%$ of group B and $32 \%$ of group C said that they had not received this information. The remaining household members could not recall whether they had or had not received information about leprosy from their children.

\section{Discussion}

In order to ascertain whether health information might be imparted from schoolchildren to their families, we first had to assess whether or not the children gained in knowledge from the health education session. We did detect significant improvement in knowledge among those educated about leprosy and a modest improvement in the controls. The change in the control group likely occurred because of a sharing of information $\mathrm{from}$ the leprosy educated groups. Alternatively, the questionnaire itself may have stimulated the group $\mathrm{C}$ students to learn more about the subject from other sources and to share this knowledge with their families. Although we could have chosen our control group from a 
different institution, we wanted to ensure that the 3 groups were comparable in all respects and therefore carried out the study in 1 school. In retrospect, it might have been wiser to go with the former option.

As noted in our previous study, in spite of an increase in knowledge on the subject, the students' attitude towards leprosy did not change and, in the case of group A students, appears to have worsened. However, unlike the results in our previous study, students did not admit to fearing the disease more after the health education session. They just did not want to have personal contact with a person with leprosy even if that person had been treated successfully.

It was interesting to note that this same attitudinal change was seen only in the families of group A students. We considered several possible explanations for these disturbing findings. First, it is well-known that change in knowledge does not in itself guarantee a change in attitude. This finding emphasizes the need for a more in-depth discussion by health educators of cultural taboos and irrational fears concerning leprosy. 'Booster doses' of health education might also help to affect an attitude change. With centuries of stigma to overcome, it may be too much to expect a single health education session to affect attitudinal changes towards leprosy.

It might have been postulated that since group A had the homework assignment to discuss with their families, pre-existing prejudice towards persons with leprosy by family members might have accounted for the worsening attitudes of group A students. However, the results of the pre-test questionnaire did not show group A family members to be more negative than the other groups towards persons with leprosy.

The more disturbing finding was the definite trend for group A family members, like their children, to reject persons with leprosy to a greater extent after the health education session. Perhaps discussions about leprosy awoke old prejudices or fears. Alternatively, it is possible, but unlikely, that during the session with students in group A, the health educator inadvertently enhanced the pupils' fear of leprosy which was then transferred to their families. Since both of our studies employing different health educators for students and families of very different backgrounds showed very similar results we are convinced that our findings reflect a definite failure of a single health education session to alter attitudes towards leprosy. We feel that more research needs to be done on ways in which knowledge of leprosy can be used to affect a change in the age-old prejudices about the disease in endemic areas.

In contrast to our previous study, there was definite transfer of health information on leprosy from children to their families. This was confirmed by the proportion of household members who could recall having received information on leprosy from their children during the study period. It was interesting to note that in the present study more than $50 \%$ of family members of the students educated on leprosy recalled learning about the subject from their children compared with only $8 \%$ in our previous study. This difference is probably explained by the fact that our previous study was carried out in a rural population of lower socioeconomic status compared with a well-educated middle class population in our present study. Intuitively, one might expect more communication to occur between student and parent in the latter population. However, in spite of the study design which was geared to maximize knowledge transfer among group A students, we did not find that the homework assignment offered a significant advantage over a standard health education session.

The results of out study in South India demonstrate that by educating urban, middle 
class children about leprosy, the knowledge level and perhaps the attitudes of their families concerning leprosy can be influenced. Although our study showed that health education did not uniformly generate positive attitudes towards leprosy, a single session may not have been sufficient. It is likely that ongoing, continuous health education is needed in order to reinforce concepts and influence attitudes. More studies of this type are needed, particularly to assess the optimal types of educational activities which are most likely to affect attitudinal changes both in students and their families.

\section{Reference}

1 Premkumar R, Keystone JS, Christina M, Jesudasan K. Transmission of health information on leprosy from children to their families: another approach to health education. Lepr Rev, 1991; 62: 58-64. 